\title{
The Regional Downscaling Approach: a Brief History and Recent Advances
}

\author{
Burkhardt Rockel
}

Published online: 29 January 2015

(C) The Author(s) 2015. This article is published with open access at Springerlink.com

\begin{abstract}
In recent years, two major topics have emerged in regional climate modeling. One topic is the extension of regional climate models of the atmosphere to regional Earth system models. Specifically, the coupling of regional atmosphere-ocean models is an important step toward reducing the dependency of regional climate simulations on global models. The second topic is the decrease of the horizontal grid spacing such that convection can be explicitly computed. These topics present new challenges for the observational data used to evaluate the models. To date, gridded observation data on the kilometer scale have been only available over a few specific regions. The size of regional climate model ensembles has considerably increased in recent years. Thus, how to manage large datasets and how to select representative subsets are challenges that must be addressed. Comparatively, little progress has been achieved in the fields of boundary conditions and physical parameterizations.
\end{abstract}

Keywords Regional climate modeling - Regional climate system · Very high resolution climate modeling $\cdot$ Model evaluation $\cdot$ Model ensembles

\section{Introduction}

In the late 1980s, global climate models had a grid mesh of approximately $500 \mathrm{~km} \mathrm{[1],} \mathrm{which} \mathrm{made} \mathrm{it} \mathrm{impossible} \mathrm{to} \mathrm{obtain}$ detailed information over complex terrain. To overcome this disadvantage, Dickinson and his group set out to simulate a domain of interest with a limited area model with higher

This article is part of the Topical Collection on Advances in Modeling

B. Rockel $(\bowtie)$

Helmholtz-Zentrum Geesthacht, 21502 Geesthacht, Germany

e-mail: Burkhardt.Rockel@hzg.de resolution [2]. This group chose the mesoscale model MM4 (Penn State/NCAR Mesoscale Model version 4 [3]) with a grid mesh of $60 \mathrm{~km}$. The MM4 had previously performed well in weather forecasting simulations up to a few days. The results of 20-day simulations based on 3 to 5 days consecutive model runs were encouraging [2]. On the basis of MM4, RegCM (Regional Climate Model system), the first regional climate model (RCM), was developed and the first continuous monthly simulations were performed $[4,5]$. Scientists in Canada and Europe worked on RCMs in the 1990s by specifically developing the models for their domains of interest. Subsequently, scientists in other regions joined the RCM effort, and building a regional climate model based on a weather forecast model became a common practice. Over the next 20 years, the resolution of RCMs did not significantly change, but the length of the simulation increased from 1 month [5] to more than a century (CORDEX, Coordinated Regional Climate Downscaling Experiment, [6]). Therefore, the increase in the computing time was used to increase the simulation time of the RCMs. Over the last 5 years, RCMs were given higher resolutions, and ensembles of RCMs were created with a 12-km grid mesh size [7], which was near the limit of the hydrostatic description of the atmosphere for which most of the RCMs were built. As faster computers have become available, performing two-way coupling with regional models of other parts of the Earth system, particularly regional ocean models, has become feasible in recent years.

Since the beginning of the RCM era, many reviews have summarized the major results for specific points in time [8-12] and region [13]. A recent review on mesoscale weather forecasting models [14] described the strong relationship between RCMs and regional weather forecasting models.

In addition to these general reviews, critical reviews have revealed weaknesses in $\mathrm{RCM}$ modeling $([15 \bullet, 16 \bullet]$ are the most recent reviews). 
The present paper does not intend to review all of the aspects of regional climate modeling over the last 25 years, but it aims to comprehensively summarize the progress over the last 5 years or so, based on the personal view of the author, and to provide references for further reading. The major aspects considered in this paper are boundary conditions, very high resolution modeling, evaluation, regional climate system models, and ensembles. In a short chapter, the "added value" issue is touched, which is unavoidable when writing about regional climate modeling.

\section{Boundary Conditions}

A major issue in regional climate modeling is the transfer of large-scale information provided by the global climate model or the reanalysis to the RCM. The standard method of achieving this transfer is through the lateral boundaries by applying a technique proposed by Davies [17]. To include the large-scale information from the global model in the interior of the RCM domain, an information transfer in the spectral space that only considers the large scales of the GCM has been proposed [18, 19]. This method is known as spectral nudging. Kanamaru et al. [20] developed an alternative treatment of spectral nudging, i.e., the scale-selective bias correction; the authors added spectral damping of the wind components, an error correction to the temperature and humidity, and an error correction to the surface pressure due to the different orography of global and regional models. Since then, no new breakthroughs in boundary condition concepts have been published in recent years, except for refinements of the above-mentioned methods. However, a more detailed summary, a discussion of these methods, and general lateral boundary issues have recently been published in the literature $\left[15 \bullet, 16^{\bullet}\right]$.

The transfer of GCM information to the interior of the RCM domain must be performed with care. The process should ensure that small-scale information in the RCM is undisturbed, considering that this information is a major benefit of RCMs compared with coarse-grid GCMs. This transfer can be achieved by nudging only the large-scale information in the free atmosphere and leaving the RCM quantities in the planetary boundary layer untouched [21]. However, the latter condition is not met in most simulations performed with RCMs because of the treatment of water at the surface, i.e., the skin temperature of oceans and lakes. In this review, the expression "sea skin temperature" (SSKT) is used instead of sea surface temperature (SST) because SSKT is always defined at the lower boundary of the atmosphere, whereas the SST is defined as the upper boundary of the sea, which is underneath sea ice at high latitudes. The SSKT is obtained from the GCM, and it influences the results of the RCM. This is especially an issue for scenario simulations [22]. Addressing the issue of SSKT over oceans is challenging. A solution is the coupling of a regional ocean model with the RCM. This supports regional climate system modeling, which is addressed later in this paper.

A similar problem is the representation of the SSKT of lakes. This is especially the case where the GCM does not resolve particular lakes that are resolved by the RCM. Some solutions, such as using the nearest ocean grid point, a climatological value or the temperature of the adjacent land points, are not appropriate. Fortunately, significant progress regarding this issue has been made in recent years. The intensified research on coupling regional ocean models and lake models with RCMs has been successful. The lake model FLake [23, 24] has become popular in particular RCMs due to its simple and efficient design. A global dataset of lake coverage and depth [25] is incorporated in FLake; thus, the model is straightforward to apply for different parts of the world. It has been shown that the application of this lake model can improve the accuracy of the assumed SSKT in RCMs [26, 27]. Furthermore, several other lake parameterizations are compared in lakeMIP (lake model intercomparison project) [28].

\section{Very High Resolution}

One common issue of regional climate models is the description of convection. Several parameterization schemes have been developed over recent decades. Each of these schemes has strengths and weaknesses, and there is no single parameterization that is superior when comparing their use in different regions of the world (e.g., [29]). However, because of the increasing computing power, the use of a convective cloud parameterization may no longer be required for many applications in the near future. Climate projections with a grid spacing below $5 \mathrm{~km}$ are currently affordable as time slice simulations, e.g., [30-32]. Very high resolution models are also called convection-resolving models or cloud-resolving models. However, some clouds cannot be resolved, even with a horizontal grid resolution of $1 \mathrm{~km}$. Deep convective parameterizations are not used at this scale; however, shallow convection may still be accounted for.

An example of the positive implications of regional simulations on the convection-resolving scale was described by Ikeda et al. [33]. The authors found that a grid spacing of less than $6 \mathrm{~km}$ was required to satisfactorily simulate the seasonal snowfall over Colorado. In other studies [30, 34, 35], an increase in short-duration precipitation events over the southern UK has been identified. Kanada et al. [36] found an intensification of updrafts in the future induced by moist convection at the Pacific side of Japan resulting in intensified precipitation. Lindenberg [37] showed an improvement in the mean wind speed and the probability density functions over complex topography. Lebassi-Habtezion et al. [38] also found very high resolution simulations to improve their results due to a better 
representation of surface heterogeneity. Kanada et al. [39] suggest that very high resolution climate modeling is needed to predict future changes in extremely intense tropical cyclones. The investigations on the convective resolving scale are currently single case studies; internationally organized projects/collaborations are needed.

The daily cycle of convection is generally unrealistically described by RCMs and GCMs. The maximum convection is predicted around noon, whereas it actually occurs in the late afternoon. This discrepancy is due to the poor representation by the convection schemes applied in atmospheric models. Convection-permitting simulations have overcome this problem [31, 32, 40]. Recently, Bechtold et al. [41•] found that considering boundary layer forcing as an additional term in deep convection parameterization leads to a substantial improvement in the diurnal cycle. Although Bechtold et al. performed tests with the European Center for Medium-Scale Weather Forecast (ECMWF) model, it may also resolve the diurnal cycle problem in RCMs on non-convective permitting scales. However, the effect on climate simulations is unknown.

New challenges have emerged in model dynamics and physics regarding grid spacing on the order of $1 \mathrm{~km}$. For spacing within $10-50 \mathrm{~km}$, no significant changes were necessary; however, for a resolution on the kilometer scale, significant changes in the RCM-modeling structure are necessary. The first generation RCMs relied on the hydrostatic approximation. A non-hydrostatic core must be implemented in the older models to advance them to the level of second generation RCMs, which incorporate the complete third equation of motion. Physical parameterizations like cloud microphysics (prognostic rain, snow, and graupel/two-moment scheme) and radiative transfer parameterizations (e.g., shadowing effects in mountainous regions) are also impacted.

The RCMs that remain strongly linked to the weather forecast model on which they were built have an advantage when moving to very high resolutions. Numerical weather prediction (NWP) centers achieved the convection-resolving scale before the RCM community. Therefore, particular issues emerging at very high resolutions have already been addressed.

A problem related to convection-permitting simulations is the lack of high-resolution spatial and temporal data for validations especially in remote regions [42]. This problem is applicable to both very high resolution and (less often) low resolution model setups, as discussed in the next section of this paper.

\section{Evaluation}

A common method used to evaluate RCMs is to run simulations with global reanalysis data, which are regarded as perfect boundary conditions (downscaling type 2 after Castro et al. [43]), and to compare the results with observations. Although high-resolution gridded datasets on climatological background fields (e.g., orography, land-sea mask) with grid mesh sizes of $1 \mathrm{~km}$ are available; only a few high-resolution datasets on meteorological quantities are available over limited areas (e.g., $[44,45])$. The lack of high-resolution data for validation was noted 10 years ago [46]. This lack of data causes a fundamental dilemma in evaluating RCMs on smaller scales, which are expected to provide added value [47] to these scales. Commonly used global gridded datasets have a $0.5^{\circ}$ grid size and a monthly frequency, which is sufficient to determine the performance of global climate models but is no longer sufficient for the latest high-resolution RCM simulations. Xue et al. [15•] suggest to use regional reanalysis and high-resolution observational data to account for the representation of small-scale features. Using high-resolution data, higher order moment statistics can be applied rather than the mean values only.

Because RCMs are only approximations of the real world, they will never be able to describe Earth system processes in detail. However, RCM modelers aim to develop the most realistic models possible. The preferred procedure is to improve the model sub-modules for dynamics and physics (e.g., clouds, convection, turbulence, and radiation) when using more complex parameterizations. Additional improvements can be achieved by using tuning parameters (e.g., changing empirical constants in their range of uncertainty) or nudging. These are applied internally, affect the entire model performance, preserve the consistency between model quantities, and thus are the preferred methods to improve the RCM results. However, the improvements due to the better parameterizations and internal tuning remain unsatisfactory because the demands of the public and climate impact modelers are still not met. Additional time is required to reach a sufficient level of accuracy. To overcome this problem, applying an external correction (a "bias correction") has become popular [48-50]. The model output quantities (primarily precipitation and near-surface temperature) are corrected using observational data. The correction algorithms [50] are then applied to the results of the climate projections. The value of these external corrections is debated in the RCM community [51] because of associated problems, for example, retaining the consistency between the corrected quantities and the validity of the derived bias-correction algorithm for future scenarios and the different RCM-GCM combinations.

\section{Regional Climate System Models}

The focus of RCMs is on the description of the atmosphere. Interactions with other components of the Earth system (biosphere, lithosphere, cryosphere, and hydrosphere) are 
parameterized in RCMs in a simplistic manner. Because of the increasing computing power, coupling RCMs with specialized regional models of the ocean, sea ice, and chemistry/ aerosols, among others, has become affordable. Recently, these coupled modeling systems are called regional climate system models (RCSMs) or regional Earth system models (RESMs). The initial ideas for these models were described 20 years ago by Giorgi [52].

As previously noted in the section on boundary conditions, the GCM greatly influences the free development by means of the SSKT, which is an input from a large-scale model to an RCM. The strongest impacts occur where the atmosphereocean interaction is important $[22,53]$. The coupling of regional atmosphere, ocean, and sea ice models can overcome this problem. Therefore, it is not surprising that most of the newly developed RCSMs are coupled atmosphere-ocean-sea ice model systems [54]. In order to understand biogeophysical feedbacks, RCMs have to be coupled to dynamic vegetation models $[55,56]$. The influence of aerosols on cloud formation and radiative transfer is well known; however, studies using RCMs coupled with chemistry/aerosol models like [57] were rare in the past. This changed over the last years, and the importance of aerosol forcing on regional climate was shown in several publications [58-62].

In the Med-CORDEX (Mediterranean-CORDEX) project, the first ensemble of fully coupled RCSMs is planned for climate projections. The initial ensemble simulation has already been successfully conducted with coupled regional atmosphere-land-ocean models over the Mediterranean. Additional components (e.g., aerosols, dynamical vegetation, lakes, and ocean biogeochemistry) may be added to the modeling system [63].

The exchange of information between the models can be performed by direct coupling through subroutine interfaces or an external coupler. In direct coupling, one of the models has the role of the "parent", which requires input information to be provided to its "children" via subroutine interfaces. In the application of an external coupler [64-66], all of the models are treated equally. The latter is more flexible due to its modular design; however, it requires more computing resources.

\section{Ensembles}

A $1 \times 1 \times 1$ regional climate projection in which one $\mathrm{RCM}$ is driven by one GCM for one greenhouse gasses forcing scenario is inadequate because it only describes one possible future climate. An $\mathrm{nr} \times \mathrm{ng} \mathrm{x}$ ns matrix of climate projections with nr RCMs driven by ng GCMs for ns scenarios is required to determine the spread in the climate projections. Many projects over the last 10 years have followed this approach [67-72]. All of these projects were coordinated independently in the specific regions for which they were designed. Within the framework of CORDEX [6], there has been an ongoing effort to coordinate regional climate modeling across all continents. The driving GCM data are those available through the Coupled Model Intercomparison Project Phase 5 (CMIP5, http://cmip-pcmdi.llnl.gov/cmip5/).

In recent years, the number of GCM simulations (additional GCMs and more realizations of individual GCMs) and the number of participating groups running RCM simulations have steadily increased. Individual RCMs are currently more modular; different types of physical and dynamic packages can be selected. Thus, only the basic framework of the model remains the same [73]. As a result, the number of possible simulations in the climate projection matrix is further increased.

In the upcoming regional climate system models, an additional dimension, nc, in the model ensemble matrix is introduced by coupling models that describe different parts of the Earth system (e.g., ocean, ice, and vegetation) to an individual atmospheric RCM. Completely filling the entire $n r \times n g \times n s \times n c$ matrix would strain the resources of the participating institutions. Therefore, RCM modelers have been confronted with the task of selecting an optimal sub-set of GCMs to drive their models [74-79]. For CMIP5, McSweeney et al. [80] recently proposed a selection process over multiple regions that eliminates unrealistic GCMs while maintaining maximum spread; one criterion is the representation of the key circulation features.

The interpretation of the results from the RCM ensemble raises questions about the treatment of the results from individual models. Should all of the results be considered equally, or should the results be weighted? Which quantities should form the basis of the weighting, and are they all equally important? Should only the RCMs be weighted, or should the combined GCM-RCM simulations be weighted? These questions and related problems are described in the literature [81, 82]. However, a robust and reliable weighting scheme has yet to be developed.

The results from RCM ensembles are used by scientists as input for their models. These scientists must choose the optimum sub-ensemble of the RCM results. To choose a representative number of RCMs, hierarchical clustering has been proposed [83] similar to the GCM selection for RCMs [76].

\section{Added Value}

The question on what can be gained by using RCMs instead of GCMs (the "added value" question) is an ongoing issue in regional climate modeling. When Giorgi and colleagues in the late 80 's looked for a way to answer scientific questions in connection with orography; they found GCMs not to be the appropriate tool due to their coarse resolution. The solution was a model with higher resolution but for a limited area, the 
RCM. In the following years up to now, the question "What is the appropriate tool to answer my scientific question?" was not always posed carefully enough, but the RCMs were used right away. Doing so, one comes under pressure for failing an explanation on the added value. An example is using RCMs for describing mean values over larger areas or monthly mean values. This can also be achieved by GCMs.

Numerous publications are dedicated to the question of added value in the last years. A review on the added value for several different atmospheric parameters is given by Feser et al. [47]. Especially they showed the added value in simulating storms like polar lows and tropical cyclones. The better description of fine scale features on spatial and temporal scales by RCMs is described in [40, 84-86]. In atmospheric quantities, this can be well identified in precipitation especially over complex terrains. Extremes like heavy rainfall and sweltering days are other examples for better representation in RCMs (e.g., [87]). In general, studies on very high resolution (see the corresponding chapter in this publication) show an added value of RCMs.

It should be noted that the quality of RCM results is influenced by the quality of the boundary conditions provided by the driving GCM, i.e., errors in the large field of the GCM will reflect in the RCM results [84]. Therefore, the added value must be assessed by comparing the RCM performance to that one of its driving GCM.

\section{Conclusions}

During the first 20 years of RCM development, increasing computing resources were primarily used to achieve higher resolution and longer simulations. This achievement was possible with only modest changes in the models, except for the parallelization to efficiently use modern computers. Recently, RCM modelers have addressed the following challenges:

1. The shift from RCMs to regional climate system models. Existing couplers [64-66] have helped solve the technical aspect of this shift; however, deciding what (e.g., which state variables of fluxes) to exchange or adapt in each model to create a realistic interplay cannot be solved universally; thus, individual RCMs must solve this problem.

2. Transferability. RCMs were developed to simulate climate changes at a higher resolution than GCMs over a particular region. RCMs are evaluated over the represented region and are improved to provide the best possible results in that region. This characteristic is an advantage compared with GCMs, which aim to provide good results over the entire Earth by using universally valid parameterizations. However, the application of an RCM in only one region is no longer valid. Currently, RCMs are also used in regions for which they were not developed. Since the start of CORDEX, this process has accelerated. A model can be modified by one of the following methods to achieve the best performance in different regions. An RCM can be adapted to each chosen region individually, which leads to different versions of an RCM for different regions. Alternatively, a universal version of the RCM can be applied to different regions without adaptation. In the second option, one of the advantages of RCMs over GCMs is lost.

3. Very high resolution. Decreasing the grid spacing of an RCM to very high resolution will exceed the resolution limit for which the hydrostatic approximation is no longer valid. Also, physical parameterizations need to be adopted which leads to substantial changes in the RCM code.

It may be possible to run RCMs on the kilometer scale over large (continental) areas and for long continuous simulations in the near future; however, whether this implementation is required or a waste of computing resources is debatable. Studies in the coming years may reveal whether the simulations for local domains are sufficient replacements for continental simulations. The telescoping approach previously proposed for numerical weather prediction in the late 1960s [88] and recently introduced for regional climate modeling [89] is worth considering in this context. Multiple nesting maintains the number of grid points for each nesting step and zooms into a local area for the highest resolution. A positive implication of this approach is that the increase in the computing time is primarily the ratio of the different time steps in the lowand high-resolution model setup. Event-based simulations are another option for the efficient use of computing resources; however, the efficient selection of these events must be considered. A combination of highresolution RCMs with statistical downscaling methods to achieve higher resolutions is a viable option in the future. Models for specific local regions (e.g., urban models for specific cities) that are modularly coupled through external couplers are also an option.

The collaboration between the regional climate modeling community and the NWPs has historically been poor regarding the continuous development of unified weather forecasting and regional climate modeling systems. Better cooperation between the climate and weather forecasting communities regarding these unified systems should be fostered in the future. This cooperation would benefit both communities and the public. Additionally, including also GCMs, this would cover the global to regional scales and the weather forecasting to climate scales (e.g., [90, 91]).

What is the value of a regional climate model? Scientifically, we can explore higher order statistics; however, for stakeholders, these are difficult to understand. The scientist to stakeholder translation (and vice versa) problem has been 
given more attention in recent years (e.g., [92]). Scientists that engage in communicating with the public and stakeholders with scientific backgrounds represent an ideal link between the scientific community and the public.

Conflict of Interest The author states that there is no conflict of interest.

Open Access This article is distributed under the terms of the Creative Commons Attribution License which permits any use, distribution, and reproduction in any medium, provided the original author(s) and the source are credited.

\section{References}

Papers of particular interest, published recently, have been highlighted as:

- Of importance

1. Williamson DL, Kiehl, JT, Ramanathan V, Hack JJ. Description of NCAR community climate model (CCM1) Natl. Atmos. Res. Tech. Note NCAR/TN-285+STR. (1987).

2. Dickinson RE, Errico RM, Giorgi F, Bates GT. A regional climate model for the Western United States. Clim Change. 1989;15:383-422.

3. Anthes RA, Hsie EY, Kuo YH. Description of the Penn State/ NCAR mesoscale model version 4 (MM4). National Center for Atmospheric Research, Boulder. (1987).

4. Giorgi F, Bates GT. AMS Journals Online-The climatological skill of a regional model over complex terrain. Monthly Weather Review. (1989).

5. Giorgi F. Simulation of regional climate using a limited area model nested in a general circulation model. J Climate. 1990;3:941-63.

6. Giorgi F, Jones C, Asrar GR. Addressing climate information needs at the regional level: the CORDEX framework. WMO Bull. 2009;58:175-83.

7. Jacob D, Petersen J, Eggert B, Alias A, Christensen OB, Bouwer LM, Braun A, Colette A, Déqué M, Georgievski G, Georgopoulou E, Gobiet A, Menut L, Nikulin G, Haensler A, Hempelmann N, Jones C, Keuler K, Kovats S, Kröner N, Kotlarski S, Kriegsmann A, Martin E, Meijgaard E, Moseley C, Pfeifer S, Preuschmann S, Radermacher C, Radtke K, Rechid D, Rounsevell M, Samuelsson P, Somot S, Soussana JF, Teichmann C, Valentini R, Vautard R, Weber B, Yiou P. EURO-CORDEX: new high-resolution climate change projections for European impact research. Reg Environ Change. (2013).

8. Giorgi F, Mearns LO. Approaches to the simulation of regional climate change: a review. Rev Geophys. 1991;29:191-216.

9. Giorgi F, Mearns LO. Introduction to special section: regional climate modeling revisited. J Geophys Res. 1999;104:6335.

10. Wang Y, Leung LR, McGregor JL, Lee D-K, Wang W-C, Ding Y, et al. Regional climate modeling: progress, challenges, and prospects. J Meteorol Soc Jpn. 2004;82:1599-628.

11. Foley AM. Uncertainty in regional climate modelling: a review. Prog Phys Geogr. 2010;34:647-70.

12. Rummukainen $\mathrm{M}$. State-of-the-art with regional climate models. Wiley Interdiscip Rev Clim Chang. 2010;1:82-96.

13. Solman SA. Regional climate modeling over South America: a review. Adv Meteorol. 2013;2013:1-13.

14. Dudhia J. A history of mesoscale model development. Asia-Pacific J Atmos Sci. 2014;50:121-31.

15. Xue Y, Janjic Z, Dudhia J, Vasic R, De Sales F. A review on regional dynamical downscaling in intraseasonal to seasonal simulation/prediction and major factors that affect downscaling ability. Atmospheric Research. 2014;147-148, 68-85. Issues in lateral boundary, physical processes, domain size, position and resolution are reviewed including examples.

16. Hong S-Y, Kanamitsu M. Dynamical downscaling: fundamental issues from an NWP point of view and recommendations. Asia-Pacific J Atmos Sci. 2014;50:83-104. Issues in dynamical downscaling are reviewed critically and illustrated in several examples. At the end of the paper recommendations for possible solutions are provided.

17. Davies HC. A lateral boundary formulation for multi-level prediction models. Q J Roy Meteorol Soc. 1976;102:405-18.

18. KIDA H, Koide T, Sasaki H, Chiba M. A new approach for coupling a limited area model to a GCM for regional climate simulations. J Meteorol Soc Jpn. 1991;69:723-8.

19. von Storch $\mathrm{H}$, Langenberg H, Feser F. A spectral nudging technique for dynamical downscaling purposes. Mon Weather Rev. 2000;128: 3664-73.

20. Kanamaru H, Kanamitsu M. Scale-selective bias correction in a downscaling of global analysis using a regional model. Mon Weather Rev. 2007;135:334-50.

21. Rockel B, Castro CL, Pielke Sr RA, von Storch H, Leoncini G. Dynamical downscaling: assessment of model system dependent retained and added variability for two different regional climate models. J Geophys Res. 2008;113, D21107.

22. Kjellström E, Ruosteenoja K. Present-day and future precipitation in the Baltic Sea region as simulated in a suite of regional climate models. Clim Change. 2007;81:281-91.

23. Mironov D, Heist E, Kourzeneva E, Ritter B, Schneider N, Terzhevik A. Implementation of the lake parameterisation scheme FLake into the numerical weather prediction model COSMO. Boreal Environ Res. 2010;15:218-30.

24. Mironov D, Ritter B, Schulz J-P, Buchhold M, Lange M, Machulskaya E. Parameterisation of sea and lake ice in numerical weather prediction models of the German Weather Service. Tellus A. 2012;64:1034.

25. Kourzeneva E, Asensio H, Martin E, Faroux S. Global gridded dataset of lake coverage and lake depth for use in numerical weather prediction and climate modelling. Tellus A. 2012;64:1.

26. Gula J, Peltier WR. Dynamical downscaling over the great lakes basin of North America using the WRF regional climate model: the impact of the great lakes system on regional greenhouse warming. J Climate. 2012;25:7723-42.

27. Samuelsson P, Kourzeneva E, Mironov D. The impact of lakes on the European climate as simulated by a regional climate model. Boreal Environ Res. 2010;15:113-29.

28. Stepanenko VM, Goyette S. First steps of a lake model intercomparison project: lakemiP. Boreal Environ. Res. (2010).

29. Meinke I, Roads J, Kanamitsu M. Evaluation of RSM-simulated precipitation during CEOP. J Meteorol Soc Jpn. 2007;85A:145-66.

30. Kendon EJ, Roberts NM, Fowler HJ, Roberts MJ, Chan SC, Senior CA. Heavier summer downpours with climate change revealed by weather forecast resolution model. Nat Clim Chang online. 2014. doi:10.1038/nclimate2258.

31. Ban N, Schmidli J, Schär C. Evaluation of the convection-resolving regional climate modeling approach in decade-long simulations. J Geophys Res Atmos. 2014;119:7889-907.

32. Fosser G, Khodayar S, Berg P. Benefit of convection permitting climate model simulations in the representation of convective precipitation. Clim Dyn online. 2014. doi:10.1007/s00382-014-2242-1.

33. Ikeda K, Rasmussen R, Liu C, Gochis D, Yates D, Chen F, et al. Simulation of seasonal snowfall over Colorado. Atmos Res. 2010;97:462-77.

34. Kendon EJ, Roberts NM, Senior CA, Roberts MJ. Realism of rainfall in a very high-resolution regional climate model. J Climate. 2012;25:5791-806. 
35. Chan SC, Kendon EJ, Fowler HJ, Blenkinsop S, Ferro CAT, Stephenson DB. Does increasing the spatial resolution of a regional climate model improve the simulated daily precipitation? Clim Dyn. 2012;41:1475-95.

36. Kanada S, Nakano M, Kato T. Changes in mean atmospheric structures around Japan during July due to global warming in regional climate experiments using a cloud-system resolving model. Hydrol Res Lett. 2010;4:11-4.

37. Lindenberg J. A verification study and trend analysis of simulated boundary layer wind fields over Europe. Helmholtz-Zentrum Geesthacht, Geesthacht. (2011).

38. Lebassi-Habtezion B, Diffenbaugh NS. Nonhydrostatic nested climate modeling: a case study of the 2010 summer season over the Western United States. J Geophys Res Atmos. 2013;118(10):944 10,962 .

39. Kanada S, Wada A, Sugi M. Future changes in structures of extremely intense tropical cyclones using a 2-km mesh nonhydrostatic model. J Climate. 2013;26:9986-10005.

40. Prein AF, Gobiet A, Suklitsch M, Truhetz H, Awan NK, Keuler K, et al. Added value of convection permitting seasonal simulations. Clim Dyn. 2013;41:2655-77.

41. Bechtold P, Semane N, Lopez P, Chaboureau J-P, Beljaars A, Bormann N. Representing equilibrium and nonequilibrium convection in large-scale models. J Atmos Sci. 2014;71:734-53. Potential of solving the issue of wrong daily precipitation cycle in the parameterization of convection.

42. Lucas-Picher P, Wulff-Nielsen M, Christensen JH, Aðalgeirsdóttir G, Mottram R, Simonsen SB. Very high resolution regional climate model simulations over Greenland: identifying added value. J Geophys Res. 2012;117, D02108.

43. Castro CL, Pielke Sr RA, Leoncini G. Dynamical downscaling: assessment of value retained and added using the regional atmospheric modeling system (RAMS). J Geophys Res. 2005;110, D05108.

44. Rauthe M, Steiner H, Riediger U, Mazurkiewicz A, Gratzki A. A Central European precipitation climatology-Part I: generation and validation of a high-resolution gridded daily data set (HYRAS). Meteorol Z. 2013;22:235-56.

45. Di Luzio M, Johnson GL, Daly C, Eischeid JK, Arnold JG. Constructing retrospective gridded daily precipitation and temperature datasets for the conterminous United States. J Appl Meteorol Climatol. 2008;47:475-97.

46. Leung LR, Mearns LO, Giorgi F, Wilby RL. Regional climate research. Bull Am Meteorol Soc. 2003;84:89-95.

47. Feser F, Rockel B, von Storch H, Winterfeldt J, Zahn M. Regional climate models add value to global model data: a review and selected examples. Bull Am Meteorol Soc. 2011;92:1181-92.

48. Piani C, Haerter JO, Coppola E. Statistical bias correction for daily precipitation in regional climate models over Europe. Theor Appl Climatol. 2009;99:187-92.

49. Themeß1 MJ, Gobiet A, Heinrich G. Empirical-statistical downscaling and error correction of regional climate models and its impact on the climate change signal. Clim Change. 2011;112:449-68.

50. Teutschbein C, Seibert J. Bias correction of regional climate model simulations for hydrological climate-change impact studies: review and evaluation of different methods. J Hydrol. 2012;456457:12-29.

51. Ehret U, Zehe E, Wulfmeyer V. HESS opinions "Should we apply bias correction to global and regional climate model data?" Hydrol. Earth Syst. Sci. Discuss. (2012).

52. Giorgi F. Perspectives for regional earth system modeling. Global Planet Change. 1995;10:23-42.

53. Ratnam JV, Giorgi F, Kaginalkar A, Cozzini S. Simulation of the Indian monsoon using the RegCM3-ROMS regional coupled model. Clim Dyn. 2008;33:119-39.
54. Bärring L, Reckermann M, Rockel B, Rummukainen M. eds. Third International Lund Regional-Scale Climate Modelling Workshop, Workshop Proceedings. International Baltic Earth Secretariat Publication. (2014).

55. Zhang W, Jansson C, Miller PA, Smith B, Samuelsson P. Biogeophysical feedbacks enhance Arctic terrestrial carbon sink in regional Earth system dynamics. Biogeosci Discuss. 2014;11: 6715-54.

56. Ge Q, Zhang X, Zheng J. Simulated effects of vegetation increase/ decrease on temperature changes from 1982 to 2000 across the Eastern China. Int J Climatol. 2014;34:187-96.

57. Giorgi F, Bi X. Direct radiative forcing and regional climatic effects of anthropogenic aerosols over East Asia: a regional coupled climate-chemistry/aerosol model study. J. Geophys. Res. 2002;1074439-AAC 7-18.

58. Gao Y, Zhao C, Liu X, Zhang M, Leung LR. WRF-Chem simulations of aerosols and anthropogenic aerosol radiative forcing in East Asia. Atmos Environ. 2014;92:250-66.

59. Han Z, Li J, Xia X, Zhang R. Investigation of direct radiative effects of aerosols in dust storm season over East Asia with an online coupled regional climate-chemistry-aerosol model. Atmos Environ. 2012;54:688-99.

60. Li J, Han Z, Xie Z. Model analysis of long-term trends of aerosol concentrations and direct radiative forcings over East Asia. Tellus B. 2013;65:193.

61. Nabat P, Somot S, Mallet M, Sevault F, Chiacchio M, Wild M. Direct and semi-direct aerosol radiative effect on the Mediterranean climate variability using a coupled regional climate system model. Clim Dyn. (2014).

62. Zanis P, Ntogras C, Zakey A, Pytharoulis I, Karacostas T. Regional climate feedback of anthropogenic aerosols over Europe using RegCM3. Climate Res. 2012;52:267-78.

63. Somot S, Ruti P. The Med-CORDEX group: Med-CORDEX: a first coordinated inter-comparison of fully-coupled regional climate system models (RCSM) for the Mediterranean. International Baltic Earth Secretariat. Publication. 2014;3:65-6.

64. Hill C, DeLuca C, Balaji V, Suarez M, Da Silva A. Architecture of the earth system modeling framework. Comput Sci Eng. 2004;6: $18-28$.

65. Larson J, Jacob R, Ong E. The model coupling toolkit: a new Fortran90 toolkit for building multiphysics parallel coupled models. Int J High Perform Comput Appl. 2005;19:277-92.

66. Valcke S. The OASIS3 coupler: a European climate modelling community software. Geosci Model Dev. 2013;6:373-88.

67. Christensen JH, Carter TR, Rummukainen M, Amanatidis G. Evaluating the performance and utility of regional climate models: the PRUDENCE project. Clim Change. 2007;81:1-6.

68. Hewitt C, Director E. The ENSEMBLES project. EGU Newslett. (2005).

69. Mearns LO, Gutowski W, Jones R, Leung R, McGinnis S, Nunes A, et al. A regional climate change assessment program for North America. Eos Trans AGU. 2011;90:311-2.

70. Fu C, Wang S, Xiong Z, Gutowski WJ, Lee D-K, McGregor JL, et al. Regional climate model intercomparison project for Asia. Bull Am Meteorol Soc. 2005;86:257-66.

71. Curry JA, Lynch AH. Comparing arctic regional climate model. Eos Trans AGU. 2002;83:87.

72. Penalba OC, Rivera JA, Pántano VC. The CLARIS LPB database: constructing a long-term daily hydro-meteorological dataset for $\mathrm{La}$ Plata basin, Southern South America. Geosci Data J. 2014;1:20-9.

73. Evans JP, Ekström M, Ji F. Evaluating the performance of a WRF physics ensemble over South-East Australia. Clim Dyn. 2012;39: 1241-58.

74. Giorgi F, Mearns LO. Calculation of average, uncertainty range, and reliability of regional climate changes from AOGCM 
simulations via the "reliability ensemble averaging" (REA) method. Journal of Climate. (2002).

75. $\mathrm{Xu} \mathrm{Y,} \mathrm{Gao} \mathrm{X,} \mathrm{Giorgi} \mathrm{F.} \mathrm{Upgrades} \mathrm{to} \mathrm{the} \mathrm{reliability} \mathrm{ensemble} \mathrm{aver-}$ aging method for producing probabilistic climate-change projections. Climate Res. 2010;41:61.

76. Pennell C, Reichler T. On the effective number of climate models. J Climate. 2011;24:2358-67.

77. McSweeney CF, Jones RG. Ben B B booth: selecting ensemble members to provide regional climate change information. $\mathrm{J}$ Climate. 2012;25:7100-21.

78. Evans JP, Ji F, Abramowitz G, Ekström M. Optimally choosing small ensemble members to produce robust climate simulations. Environ Res Lett. 2013;8:044050.

79. Bishop CH, Abramowitz G. Climate model dependence and the replicate Earth paradigm. Clim Dyn. 2013;41:885-900.

80. McSweeney CF, Jones R. Strategic sub-selection of CMIP5 GCMs for dynamical downscaling. Int Balt Earth Secretariat Publ. 2014;3: 357-8.

81. Christensen J, Kjellström E, Giorgi F, Lenderink G, Rummukainen $\mathrm{M}$. Weight assignment in regional climate models. Climate Res. 2010;44:179-94.

82. Weigel AP, Knutti R, Liniger MA, Appenzeller C. Risks of model weighting in multimodel climate projections. J Climate. 2010;23: 4175-91.

83. Mendlik T, Gobiet A. Selecting climate simulations for impact studies based on multivariate patterns of climate change. Int Balt Earth Secretariat Publ. 2014;3:361.
84. Diaconescu EP, Laprise R. Can added value be expected in RCMsimulated large scales? Clim Dyn. 2013;41:1769-800.

85. Di Luca A, de Elia R, Laprise R. Potential for added value in precipitation simulated by high-resolution nested regional climate models and observations. Clim Dyn. 2012;38:1229-47.

86. Di Luca A, de Elia R, Laprise R. Potential for small scale added value of RCM's downscaled climate change signal. Clim Dyn. 2013;40:601-18.

87. Lee J-W, Hong S-Y. Potential for added value to downscaled climate extremes over Korea by increased resolution of a regional climate model. Theor Appl Climatol. 2013;117:667-77.

88. Hill GE. Grid telescoping in numerical weather prediction. J Appl Meteorol. 1968;7:29-38.

89. Cholette M, Laprise R. Feasibility study of very high resolution regional climate modelling through grid telescoping applied to the Canadian regional climate model (CRCM5). Int BaltEarth Secretariat Publ. 2014;3:92-3.

90. Brown A, Milton S, Cullen M, Golding B, Mitchell J, Shelly A. Unified modeling and prediction of weather and climate: a 25-year journey. Bull Am Meteorol Soc. 2012;93:1865-77.

91. Hong S-Y, Park H, Cheong H-B, Kim J-EE, Koo M-S, Jang J, et al. The global/regional integrated model system (GRIMs). AsiaPacific J Atmos Sci. 2013;49:219-43.

92. Huard D, Chaumont D, Logan T, Sottile M-F, Brown RD, St-Denis BG, et al. A decade of climate scenarios: the ouranos consortium modus operandi. Bull Am Meteorol Soc. 2014;95:1213-25. 